\section{Artificial intelligence and climate change: ethical issues}

\author{
Anders Nordgren \\ Linköping University, Linköping, Sweden
}

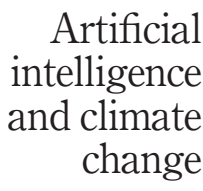

\begin{abstract}
Purpose - The purpose of this paper is to pinpoint and analyse ethical issues raised by the dual role of artificial intelligence (AI) in relation to climate change, that is, $\mathrm{AI}$ as a contributor to climate change and $\mathrm{AI}$ as a contributor to fighting climate change.

Design/methodology/approach - This paper consists of three main parts. The first part provides a short background on AI and climate change respectively, followed by a presentation of empirical findings on the contribution of AI to climate change. The second part presents proposals by various AI researchers and commentators on how AI companies may contribute to fighting climate change by reducing greenhouse gas emissions from training and use of $\mathrm{AI}$ and by providing $\mathrm{AI}$ assistance to various mitigation and adaptation measures. The final part investigates ethical issues raised by some of the options presented in the second part.

Findings - AI applications may lead to substantial emissions but may also play an important role in mitigation and adaptation. Given this dual role of AI, ethical considerations by AI companies and governments are of vital importance.
\end{abstract}

Practical implications - This paper pinpoints practical ethical issues that AI companies and governments should take into account.

Social implications - Given the potential impact of AI on society, it is vital that AI companies and governments take seriously the ethical issues raised by the dual role of AI in relation to climate change.

Originality/value - AI has been the subject of substantial ethical investigation, and even more so has climate change. However, the relationship between AI and climate change has received only limited attention from an ethical perspective. This paper provides such considerations.

Keywords Ethics, Climate change, Machine learning, Mitigation, Adaptation, Artificial intelligence

Paper type Conceptual paper

\section{Introduction}

Artificial intelligence (AI) has been the topic of substantial ethical investigation (for example, Bostrom, 2011; Coeckelbergh, 2020) and even more so has climate change (Gardiner et al., 2010; Gardiner, 2011; Brooks, 2021). However, the relationship between AI and climate change has to date, received only limited attention from an ethical perspective (Coeckelbergh, 2021). The aim of this paper is to pinpoint and analyse key ethical issues on this topic. It is beyond its scope to propose how to resolve the issues.

The focus is on the dual role of AI in relation to climate change. AI may, to a varying extent, contribute to climate change due to the present dependence of electricity on fossil fuels, but AI may also, in various ways, contribute to the mitigation of climate change and to the adaptation of society to the adverse effects of climate change (Victor, 2019; Dhar, 2020).

(C) Anders Nordgren. Published by Emerald Publishing Limited. This article is published under the Creative Commons Attribution (CC BY 4.0) licence. Anyone may reproduce, distribute, translate and create derivative works of this article (for both commercial and non-commercial purposes), subject to full attribution to the original publication and authors. The full terms of this licence may be seen at http://creativecommons.org/licences/by/4.0/legalcode
Received 3 November 2021 Revised 16 December 2021 Accepted 10 January 2022

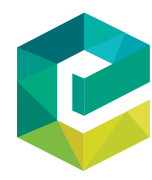

Journal of Information, Communication and Ethics in Society

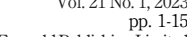
1477-996X DOI 10.1108/JCES-11-2021-0106 
JICES

21,1

The dual role of AI raises ethical issues about reducing greenhouse gas emissions from AI itself and about using AI for mitigation and adaptation. In addition to these climaterelated ethical issues, many other ethical issues are raised by $\mathrm{AI}$ in general, such as privacy issues and risk for bias (Bostrom, 2011; Floridi et al., 2018; Dignum, 2019; Coeckelbergh, 2020). These general ethical issues may hold also for this kind of use of AI. However, they will not be discussed in this paper. Moreover, ethical issues raised by climate change mitigation and adaptation, in general, will be addressed only indirectly. The key focus is on ethical issues specific to AI in relation to climate change.

The paper consists of three main parts. The first part begins with a short background on $\mathrm{AI}$ and climate change followed by a presentation of empirical findings on the contribution of AI to climate change. The second part provides examples of how AI companies may contribute to fighting climate change by reducing greenhouse gas emissions from training and use of $\mathrm{AI}$ and by providing $\mathrm{AI}$ assistance to various mitigation and adaptation measures. The final part investigates ethical issues raised by some of the options presented in the second part. It should be noted that the proposals by AI researchers and commentators presented in the second part are selected to illustrate the multitude of options. However, the presentation is not intended to be all-encompassing. It only provides a practical and technological background to the ethical investigation, which constitutes the key part of the paper.

\section{Artificial intelligence as contributor to climate change}

Let me begin by giving a short background on what AI is and its potential impact on society, and on climate change, and its adverse effects. After this, we turn to empirical studies of the contribution of AI to climate change.

\section{Artificial intelligence}

$\mathrm{AI}$ is a kind of information and communication technology (ICT) that displays or simulates human intelligence. It can be software running on the internet, for example, search engines, image analysis or bots, but also software embedded in cars, robots or "the internet of things". Many important AI applications include machine learning, that is, software that learns autonomously by finding rules or patterns that the programmer has not specified but which are based on statistics on big amounts of data. AI can be applied in several societal domains such as industry, transportation, agriculture, health care, education, finance, entertainment and social media. It may make existing processes and activities more efficient but also generate complete novelties. It has the potential for an enormous impact on society now and in the near and distant future (Coeckelbergh, 2020).

\section{Climate change}

Climate change is believed by most scientists to be a disastrous threat. A clear example is a recent statement by more than 11,000 scientists:

Scientists have a moral obligation to clearly warn humanity of any catastrophic threat and to "tell it like it is" [...]. [W]e declare, with more than 11,000 scientist signatories from around the world, clearly and unequivocally that planet Earth is facing a climate emergency (Ripple et al., 2020).

Climate change is here described as an "emergency", that is, as a very serious and urgent problem. It is a very serious problem because it is expected to have adverse effects such as extreme weather events, drought, wildfires, flooding and sea-level rise. It is a very urgent problem because some of these effects can already be seen at present at $1.1^{\circ} \mathrm{C}$ above preindustrial levels [Intergovernmental Panel on Climate Change (IPCC), 2021, pp. 5, 15-30]. 
These effects will become worse at $1.5^{\circ} \mathrm{C}$ and more so at $2.0^{\circ} \mathrm{C}$ - the goals of the 2015 Paris Agreement [United Nations Framework Convention on Climate Change (UNFCCC), 2015]. If climate change continues to be unmitigated or only poorly mitigated, the average global temperature is expected to reach $3^{\circ} \mathrm{C}$ by 2100 (Hausfather and Peters, 2020) or even higher (Schwalm et al., 2020) with even more catastrophic effects.

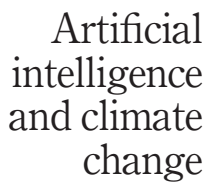

Emissions from artificial intelligence applications

AI is often presented as "clean tech". For example, Apple and Google maintain that they are carbon neutral (due to the purchase of emission credits), and Microsoft announces that it will be carbon negative by 2030 (Crawford, 2021, p. 43). However, it is unclear how large the emissions actually are. The companies are not open to this. Transparency is lacking (Crawford, 2021, p. 41). To get some understanding, we need to look at independent studies.

Support for the projection that AI will contribute substantially to climate change can be found in studies of the actual and expected carbon footprint of ICT in general (Andrae and Edler, 2015; Hazas et al., 2016; International Energy Agency (IEA), 2017; Belkhir and Elmeligi, 2018; Jones, 2018; Unwin, 2020). It can also be found in studies of the footprint of individual AI applications (Strubell et al., 2019; Anthony et al., 2020). Let us have a closer look at two studies, one of each type.

An important study of the carbon footprint of the ICT sector, in general, was carried out by Belkhir and Elmeligi (2018). The scope of the study was computing devices (for example, desktops, laptops, smartphones and tablets), data centres and communication networks. The study excluded, for example, TVs and printers (Belkhir and Elmeligi, 2018). This is how Belkhir and Elmeligi summarized their study:

We have conducted in this study what we believe to be the most detailed, precise and methodical analysis of the ICT global GHGE footprint, which includes both the production and the operational energy of ICT devices, as well as the operational energy for the supporting ICT infrastructure. We have found that the ICT GHGE contribution relative to worldwide footprint will roughly double from 1 to $1.6 \%$ in 2007 to $3-3.6 \%$ by 2020 . Assuming a continued annual relative growth ranging from 5.6 to $6.9 \%$, ICT's relative contribution would exceed $14 \%$ of the 2016-level worldwide GHGE by 2040 [...] The lion share of the emissions were found [...] to be generated by the ICT infrastructure with data centers being the largest culprit (45\%) followed by communication networks (24\%) (Belkhir and Elmeligi, 2018; "GHGE" means "greenhouse gas emissions").

We see here that the emissions from ICT, in general, are projected to exceed $14 \%$ of the global emissions by 2040, with the main part generated by the ICT infrastructure, mainly data centres and communication networks. This projection gives us reason to expect that AI, as an increasingly significant part of ICT, will also become a substantial cause of emissions (Gailhofer et al., 2021).

A study focused explicitly on AI as a contributor to climate change was conducted by Strubell et al. (2019). They investigated the carbon footprint of several different AI models. They concluded that the emissions vary significantly among models. The highest emissions were found in the training of an AI model for natural language processing (NLP). This training was estimated to emit approximately 300,000 kg CO2e (Strubell et al., 2019). As Dobbe and Whittaker point out, these emissions correspond to the emissions of approximately 125 round-trip flights from New York to Beijing (Dobbe and Whittaker, 2019). Two things should be noted here. First, the study uses a USA-wide average of the energy mix. In regions and countries with more fossil-free energy, the emissions will be lower. Second, this study concerns the training of the AI models only. The use of the models in the real world ("inference") leads to further emissions. 
JICES

21,1

These studies of ICT in general and AI more specifically indicate that AI can be expected to contribute substantially to climate change. However, lacking from these studies is an assessment of emissions due to systemic effects, for example, rebound effects (Gailhofer et al., 2021). Economists talk about the "Jevons paradox". Jevons was a 19th century British economist who argued that more efficient use of coal would not necessarily lead to less use but rather to more use (Michaels, 2012). Several types of rebound effects resulting from improved energy efficiency have been empirically established in various societal domains: direct rebounds, indirect rebounds, economy-wide rebounds and embedded rebounds (Michaels, 2012; Brockway et al., 2021). Take the example of improving the energy efficiency of cars. This may lead to increased use of cars (direct rebound), which may increase the demand for tires (indirect rebound) and to increased use of energy in restaurants and hotels visited when travelling around (economy-wide rebound). Moreover, the production of more energy-efficient cars itself also requires energy inputs to be accounted for (embedded rebound) (Michaels, 2012). Let us assume that the energy efficiency of the cars in this example is improved by means of AI. On this assumption, the example indicates that the use of AI might have a multitude of rebound effects. To put it more generally, improved energy efficiency by using AI might increase the demand of AI applications in various societal domains and thereby increase the total use of energy in society. To the extent this energy is based on fossil fuels, the climate risks are obvious.

A special comment on the embedded rebounds of AI seems warranted. These rebounds include not only factory production of hardware and other devices necessary for AI, for example, computers, data servers, cables and batteries for electric vehicles. They include also the extraction of metals such as lithium and cobalt and other materials. Moreover, they include transport of these materials to factories for the production of components, followed by transport to other factories for the production of the end-product. Finally, the devices are transported to AI developers and users. To the extent fossil fuels are used, each step in the production chain leads to greenhouse gas emissions, and all these emissions should be included among the total emissions from AI (Crawford, 2021, pp. 23-51).

In sum, due to its potential impact in various societal domains, AI can be expected to require vast amounts of energy, and at present and in the near future, this energy comes to a large extent from fossil fuels. This leads to substantial greenhouse gas emissions. It seems fair to conclude that AI might be a significant contributor to climate change.

\section{Options for fighting climate change}

As pointed out in the Introduction, AI has a dual role in relation to climate change. It is not only a contributor to climate change but potentially also a contributor to fighting climate change. AI applications may assist in various mitigation and adaptation measures. This means that companies providing these AI applications may play a key role in fighting climate change. However, we have seen that training and use of AI may lead to substantial emissions. Therefore, AI companies first of all need to reduce their own emissions.

With this in mind, AI companies could fight climate change in at least three ways. First, they could reduce the emissions from training and use of AI and thereby contribute to the mitigation of climate change. Second, they could provide AI assistance to mitigation measures in various societal domains. Third, they could provide AI assistance in adaptation to the adverse effects of climate change.

Let us have a look at a variety of options proposed by various AI researchers and commentators. It should be noted that while the options regarding mitigation and adaptation concern AI applications as such, the options regarding the reduction of emissions from AI mainly concern infrastructure, energy sources and various restrictions on the training and use of AI. 
Reducing emissions from artificial intelligence

Greenhouse gas emissions from AI could be reduced in several different ways.

Improved energy efficiency. AI companies may make training and use of AI more energyefficient, for example, by using more efficient hardware or reducing the energy needed for cooling in data centres (Lacoste et al., 2019; Walleser, 2021). Another measure could be to reduce the amount of data used in training AI models, that is, avoid using more data than necessary (Toews, 2020). Moreover, AI models could be scaled down. Bigger is not always better. Generating larger and larger models merely to achieve smaller and smaller improvements (diminishing returns) might be questionable from a climate change perspective (Toews, 2020).

Fossil-free energy. An important option is to see to it that the infrastructure (data centres, communication networks) uses less or no fossil fuels (Tech Workers Coalition, 2019). For example, when using cloud computing, data centres could be moved to countries or regions providing a more fossil-free energy mix (Lacoste et al., 2019).

No artificial intelligence services to the fossil fuel industry. At present, several partnerships exist between big tech companies, for example, Google, Amazon, Microsoft and big oil companies (Crawford, 2021, p. 44; Malliaraki, 2020). An option for reducing emissions from AI could be to reject such contracts (Tech Workers Coalition, 2019; Dobbe and Whittaker, 2019).

Limited use of artificial intelligence. A radical measure could be to limit the use of AI in some societal domains. This would be in line with the vision of "decent living with minimum energy" put forward by Millward-Hopkins and colleagues (Millward-Hopkins et al., 2020). For example, many uses of AI for fighting climate change or improving health care might be acceptable, but perhaps not all kinds of use for luxury or entertainment.

\section{Using artificial intelligence for mitigation}

Here are some options for how AI could be used for mitigation.

More efficient use of energy. A key option is using AI applications for more efficient use of energy in society, for example, for the construction of more energy-efficient buildings. AI may also contribute to designing better materials for solar panels, creating low-carbon materials, better monitoring of deforestation and greener transportation. Moreover, AI may assist in the allocation of fossil-free energy and make energy supply more efficient (Cho, 2018; Rolnick et al., 2019; Malliaraki, 2020).

Improved climate models. An obvious mitigation option is to use AI for improving climate models (Rolnick et al., 2019). More precise knowledge of climate change and its impact may motivate governments, communities, companies and individuals to make stronger efforts of mitigation.

Steering human behaviour. AI may also be used for steering human behaviour in a climate-friendly direction. AI may assist governments in attaining national and international climate goals by making climate nudging and regulation more efficient (Coeckelbergh, 2021).

\section{Using artificial intelligence for adaptation}

Some options for the use of $\mathrm{AI}$ in adaptation measures are listed below.

More secure supply of energy and more efficient use of energy. AI may make electric grids more secure. It could also improve efficiency and thereby reduce the demand for energy (Rolnick et al., 2019). 
JICES

21,1

Increased resilience and prevention. AI could contribute to a more resilient design, for example, of buildings, roads, bridges and sea walls as well as better prevention of water pollution and spreading of diseases (Victor, 2019; Rolnick et al., 2019).

Improved weather forecasts. AI may provide better weather forecasts and thereby contribute to better protection from extreme weather events. AI may, for example, assist in predicting the trajectory and magnitude of storms and hurricanes as well as the start of periods of drought or flooding. AI may also provide early crop forecasting systems in agriculture. It may help adjusting seeds, planting times and cropping methods to reduce harmful impacts of adverse weather events (Cho, 2018; Rolnick et al., 2019).

\section{Ethical issues}

All these options proposed by various AI researchers and commentators concern what could be done concerning AI in relation to climate change. However, the options also raise ethical issues, that is, issues about what should be done:

- How should emissions from training and use of AI be reduced?

- How should AI be used for mitigation?

- How should AI be used for adaptation?

I limit my investigation of these three climate-related ethical issues to four key aspects: usefulness, freedom, justice and responsibility. Moreover, I only investigate ethical issues raised by some of the options presented in the previous section, not all of them.

As mentioned above, the options regarding mitigation and adaptation concern AI applications as such, whereas the options regarding the reduction of emissions from AI mainly concern infrastructure, energy sources and various restrictions on the training and use of AI. These differences in the character of the options have ethical implications. The options raise different types of ethical issues. The emphasis of the analysis is on general considerations, but special attention is given to particularly contested issues. Regarding measures for reducing emissions from the AI itself, I focus specifically on the option of limiting the use of AI in some societal domains (in the subsection on freedom) and the option of not selling AI services to the fossil fuel industry (in the subsection on responsibility). Less controversial options such as improving the energy efficiency of AI applications and turning to fossil-free energy sources will be addressed only very briefly (in the subsection on responsibility). Regarding mitigation and adaptation measures, the focus is specifically on cost/benefit balancing (in the subsection on usefulness), steering human behaviour by means of AI (in the subsection on freedom), using AI in assisting low-income countries (in the subsection on justice) and special obligations of AI companies and governments (in the subsection on responsibility).

\section{Usefulness}

The usefulness of various AI applications for mitigation or adaptation may differ. Two key ethical issues arise in this context:

- How should the various options for using AI in mitigation and adaptation be prioritized?

- How should the expected benefits and costs of using AI for mitigation and adaptation be balanced? 
Rolnick and colleagues provide an ambitious assessment of the benefits of various options for machine learning, a key form of AI. They categorize the options as "high leverage", "long term" leverage and "uncertain impact" (Rolnick et al., 2019).

The first category, high leverage options, includes options that are particularly useful. Here are some examples: predicting electricity supply and demand, providing information about mobility patterns, optimizing shipment, designing smart and resilient buildings, improving materials, developing precision agriculture, improving cooling for data centres and providing data for policymaking (Rolnick et al., 2019).

Long-term options are options with their main impact after 2040. Examples are developing fusion reactors and alternative fuels, automating large-scale afforestation, sequestering carbon dioxide, designing infrastructure and geoengineering (Rolnick et al., 2019).

The third category proposed by Rolnick and colleagues is options with uncertain impact. These options are uncertain concerning the impact on emissions (for example, due to Jevons paradox, that is, rebound effects) or uncertain concerning undesirable side effects. An example of uncertainty concerning the impact on emissions is uncertainty whether shared mobility may lead to more energy-efficient use of each car or to an increased number of people traveling by car (rather than by public transportation). Another example is uncertainty whether reduced overproduction will be energy efficient because online shopping and just-in-time manufacturing may lead to smaller and faster transport lacking the energy efficiency of aggregated transport. An example of uncertainty concerning undesirable side effects is uncertainty concerning the extent to virtual communication will truly replace physical meetings (Rolnick et al., 2019).

Given the extreme urgency of mitigation and adaptation, it might be reasonable to prioritize high leverage options. However, options that are promising in the long term might also be given some priority because mitigation and adaptation might require measures that take longer to develop and implement. Options with uncertain impact, on the other hand, might not be prioritized but rather submitted to more consequence analysis.

However, prioritizing among beneficial options is not enough. When assessing the usefulness of AI for mitigation and adaptation, we need to consider not only expected benefits but also expected costs in terms of emissions due to the use of fossil fuel energy. The expected costs are, to some extent, left out in the assessment provided by Rolnick and colleagues. They mention the potential costs of options with uncertain impact, but they do not mention the costs of high leverage options and long-term options. Some high leverage options or long-term options may have rebound effects that need to be accounted for. It is vital that the use of $\mathrm{AI}$ in mitigation and adaptation does not lead to more use of fossil-based energy than it saves in the various societal domains it is applied to. The risk for this varies among different $\mathrm{AI}$ applications for mitigation and adaptation, but it has to be taken into account. As Henderson and colleagues point out:

Deploying a large deep learning model for, say, improving the energy efficiency of a building, is not worth it if the energy costs of the model outweigh the gains (Henderson et al., 2020).

This brings us to the second key ethical issue mentioned above: how should the expected benefits and costs of using AI for mitigation and adaptation be balanced? Because options may vary in benefit as well as cost, the result of balancing may vary from case to case. However, there are different views on the likely outcome of such balancing more generally. Some may stress that AI is a "game changer" (Cho, 2018) when it comes to fighting climate change. AI can and should play a key role in mitigation and adaptation. Others may argue that $\mathrm{AI}$ is more of a problem or liability for climate change than a solution, at least as long as

\section{Artificial intelligence and climate change}


JICES

21,1

the vast amounts of energy that are required (including rebound effects) to a substantial extent are dependent on fossil fuels. What is truly significant are global political measures, including carbon pricing. The contribution of AI can be and should be only limited. Commentators who are optimistic about green growth and the potential of technological innovation may be more positive about the usefulness of AI in fighting climate change, while those stressing the necessity of degrowth and the importance of living within planetary boundaries may be more negative.

\section{Freedom}

Concerning freedom, a useful distinction is between negative freedom and positive freedom (Berlin, 1969, pp. 121-122). Applied to climate change, these concepts can be understood as follows.

Negative freedom is freedom from constraints, the freedom of companies and individuals to do whatever they want. Total freedom, in this sense, does not exist in any society. Negative freedom is always more or less constrained by laws or social norms. In the context of climate change, proposals for mitigation and adaptation measures commonly include certain restrictions on negative freedom. Positive freedom, on the other hand, is the opportunity to live in a good environment with a reasonable standard of living and a reasonable range of options for choice. Mitigation and adaptation measures are means to retain positive freedom in this sense for future generations and low-income countries, not only for present generations and high-income countries (Walls, 2021).

Given these concepts, two key ethical issues arise in the context of AI and climate change:

- To what extent should the negative freedom of companies and individuals be restricted to reduce emissions from the use of AI?

- To what extent should the negative freedom of present generation companies and individuals be restricted by AI-assisted measures of mitigation and adaptation for the sake of ensuring the positive freedom of future generation companies and individuals?

Answers to these questions require a balancing of present-day negative freedom and future positive freedom. Several possible views have been put forward, and these can be illustrated in a spectrum. At the one extreme, we find absolute laissez-faire, at the other green authoritarianism. Liberal democracies can be expected to search for a middle way in between these extremes (Coeckelbergh, 2021).

Middle positions entail at least some restrictions on negative freedom. These may range from mere recommendations and climate nudging to strict legal regulations. The regulations may be a matter of command-and-control, for example, prohibitions of products or practices (Prahl and Hofmann, 2016a). They may also be market-based measures, including cap-andtrade schemes and carbon taxes (Prahl and Hofmann, 2016b).

Let me highlight a couple of specific ethical issues concerning freedom raised by two of the options for fighting climate change listed above. The first is the option of limiting the use of AI in some societal domains to reduce emissions from the AI itself. Such limiting of the use of AI might be problematic from the perspective of freedom. Market liberals may be against all such political steering, whereas eco-socialists may not. If the general option of limiting the use of $\mathrm{AI}$ in some activities is considered acceptable, the problem arises exactly which AI applications are acceptable and which are not. As mentioned, many AI applications for fighting climate change or improving health care might be considered 
acceptable, but perhaps not all kinds of applications for luxury or entertainment. Where should the line be drawn, and how should the restrictions be regulated and enforced?

The second issue concerns the mitigation option of using AI for steering human behaviour in a climate-friendly direction. AI may assist governments in reaching nationally and internationally agreed-upon climate goals by making nudging and regulation more efficient. Behavioural economists define nudging as a matter of changing the behaviour of individuals subconsciously by changing the decision environment, the "choice architecture" (Thaler and Sunstein, 2009, p. 6). A classic example is placing healthy food, for example, fruit, at the beginning of the queue in a coffee house and unhealthy food at the end rather than the other way around. In mitigation of climate change, AI may be used to nudge individuals to a more climate-friendly behaviour (Coeckelbergh, 2021). For example, they can be nudged to reduce energy consumption during peak periods, make fewer trips by car, eat less meat or generate less waste. AI may also be used in climate regulation. On the basis of large amounts of data about the efficiency of specific regulations, it may suggest better regulations or better methods of enforcement (Rolnick et al., 2019). However, climate nudging and regulation raise questions about freedom in society. To what extent is it ethically justified to restrict the negative freedom of individuals and companies? Where should society draw the line?

\section{Justice}

Injustices in relation to climate change have received considerable attention. Low-income countries are expected to suffer more than high-income countries, whereas high-income countries have caused most of the greenhouse gas emissions. With this in mind, the United Nations Framework Convention on Climate Change stresses that justice requires highincome countries to assume stronger responsibilities than low-income countries in undertaking mitigation and adaptation measures [United Nations Framework Convention on Climate Change (UNFCCC), 1992]. These stronger responsibilities can be justified in different ways. One option is to refer to the polluter-pays principle. Historically, high-income countries have emitted much more than low-income countries and should therefore contribute more to mitigation and adaptation. Another option is to refer to the ability-to-pay principle. High-income countries are richer than low-income countries and should therefore pay more in fighting climate change. A third option is to refer to the principle of equal per capita shares. Individuals in high-income countries have emitted more than their fair shares of emissions than individuals in low-income countries and should, therefore, contribute more (Singer, 2010). It should be noted, however, that some commentators argue that the issue of responsibilities of high-income countries should be decoupled from the issue of justice and rather be based on a cost/benefit analysis (Posner and Weisbach, 2010).

By improving predictions, AI may make vulnerabilities such as flooding, droughts, climate migration and socio-economic tensions more visible (Coeckelbergh, 2020). However, AI may also play a role in fighting injustices (Uddin, 2020). Two key ethical issues arise in this context:

- How should low-income countries get equal access to AI for use in mitigation and adaptation?

- How should AI be used to assist low-income countries in mitigation and adaptation?

These questions about access to AI imply issues such as how much assistance, what kind of assistance and who should take responsibility. All these questions are difficult to answer. It seems clear, however, that many low-income countries find adaptation more urgent than mitigation. They need assistance in becoming more resilient to the adverse effects of climate 
JICES

21,1

change rather than assistance in mitigation (Bwango et al., 2000). It is vital that AI companies are responsive to the kind of assistance low-income countries themselves ask for. What adaptation measures should be used in various societal domains? And how should AI assist in this context? In distinction to mitigation, which requires global measures, adaptation is mainly a local or regional issue (Heatley, 2017; Victor, 2019).

\section{Responsibility}

AI applications may lead to substantial greenhouse gas emissions but also play an important role in mitigation and adaptation. All three ethical aspects discussed so far usefulness, freedom and justice - raise questions about responsibility:

- Who should take responsibility for the use of AI in relation to climate change?

- How should they do it?

As I use the term, "take responsibility" means "accept an obligation to do $\mathrm{x}$ and act according to this obligation".

A possible answer to the first question is "all who take part in the production or consumption of AI services", for example, AI developers, tech workers, AI companies and governments, but also individuals as consumers. However, many would argue that the main responsibility lies with AI companies (more precisely, high executives, board members and leading developers) and governments (more precisely, members of governments). AI companies develop and sell AI services for profit. Governments, on the other hand, regulate the activities of these companies nationally and by means of international agreements. Given the potential impact of AI on society, it is vital that AI companies and governments take responsibility for the development and use of AI.

Regarding the responsibility of AI companies, the AI researchers and commentators referred to in this paper seem to agree that these companies should reduce emissions from training and use of AI and provide AI assistance to mitigation and adaptation. However, their views differ on exactly how much should be done and by which measures. Moreover, they stress that AI companies should be transparent about emissions from training and use of AI models (for example, Dobbe and Whittaker, 2019; Malliaraki, 2020; Henderson et al., 2020; Crawford, 2021, pp. 41-46). Some also emphasize transparency about emissions due to rebound effects (for example, Dobbe and Whittaker, 2019; Crawford, 2021, pp. 41-46; Gailhofer et al., 2021).

Some options for reducing the emissions from training and use of AI appear to be rather uncontroversial, for example, improving the energy efficiency of AI applications and turning to fossil-free energy sources. Most would agree that if AI companies should contribute to the mitigation of climate change, they should begin by reducing emissions from their own activities. Much could be achieved by such measures. Other options, however, are more contested. In the subsection on the freedom I have already analysed the option of limiting the use of AI in some societal domains. Another controversial option is to abstain from selling AI services to the fossil fuel industry. What does the responsibility of AI companies imply: is it acceptable to sell or not? Different views on corporate social responsibility (CSR) may give different answers. According to a minimalist view, there is only one social responsibility for companies and this is to generate profit within the boundaries of the law (Friedman, 1970). On such a view, it might be acceptable to sell AI services to fossil fuel companies. However, there is also a broader view of CSR. This view states that in addition to generating profit and keeping within the boundaries of the law, companies should also follow social norms that are not codified in law. Beyond this, companies may also freely choose to contribute to the common good in various ways 
(Carroll and Buchholtz, 2006, p. 35). On this broader view, AI companies may freely adopt a policy of not selling AI services to the fossil fuel industry. Not selling such services might contribute to the common good, in this case, mitigation of climate change. Generation of profit would be of lower priority than mitigation. However, things are not as simple as these answers might suggest. First, minimalists might find it more profitable in the long term to abstain from selling AI services to fossil fuel companies and instead focus on the increasingly important fossil-free market. Thereby, the AI companies may unintentionally contribute to mitigation and adaptation. Second, those holding a broad view might argue against selling AI services to fossil fuel companies not only for reasons of contributing to the common good but also for reasons of generating profit on the growing fossil-free market.

Regarding the responsibility of governments, we saw above that the UNFCCC states that governments of high-income countries have stronger responsibilities than low-income countries in undertaking mitigation and adaptation measures (1992). In undertaking such measures, they need to take into account the dual role of $\mathrm{AI}$ in relation to climate change. However, political ideologies may differ on how to do this more precisely. As pointed out above in the section on freedom, liberal democracies will probably try to find positions in between the extremes of absolute laissez-faire and green authoritarianism (Coeckelbergh, 2021). But also, such middle positions may differ on concrete measures. What restrictions on the freedom of companies and individuals should be instituted? What about prohibitions and carbon pricing? And how should low-income countries be assisted in a fair way? What role should international cooperation play? The use of $\mathrm{AI}$ in these efforts of mitigation and adaptation is contested. To what extent should AI be used in this context? How strictly regulated should $\mathrm{AI}$ companies be?

Let us finish by a quick look at two recent contributions to the discussion of the responsibility of governments for $\mathrm{AI}$ in relation to climate change. The first example is the report "The role of Artificial Intelligence in the European Green Deal" (Gailhofer et al., 2021). This report sees the potential of AI in the mitigation of climate change but recognizes also the risk for adverse effects in terms of increased use of energy and resources. It stresses the importance of ensuring that AI systems developed by private companies adhere to sustainable development principles. To achieve this, audit and certification mechanisms are relevant options. The report also emphasizes that the EU agenda for AI to support environmental sustainability should be spread globally. The environmental potential of AI should be made available to low-income and middle-income countries (Gailhofer et al., 2021).

The second example is a study by Vinuesa et al. (2020) focusing on the relation of AI to all 17 Sustainable Development Goals and 169 targets of "The 2030 Agenda for Sustainable Development" [United Nations General Assembly (UNGA), 2015]. The study finds that AI may act as an enabler of 134 targets across all 17 goals but also inhibit 59 targets. The societal, economic and environmental outcomes of the use of AI may be positive as well as negative. Regarding climate change, the study stresses the potential of AI for climate action as well as its vast energy requirements and high emissions (Vinuesa et al., 2020). Vinuesa and colleagues conclude:

The fast development of $\mathrm{AI}$ needs to be supported by the necessary regulatory insight and oversight for AI-based technologies to enable sustainable development. Failure to do so could result in gaps in transparency, safety, and ethical standards (Vinuesa et al., 2020).

Both contributions illustrate how governments might use AI in a constructive way in fighting climate change. At the same time, they show awareness of the energy costs of this technology. However, the feasibility of these policies remains an open question.

\section{Artificial intelligence and climate change}


JICES

21,1

\section{Conclusion}

In this paper, I have pinpointed and analysed ethical issues raised by the dual role of AI in relation to climate change, that is, $\mathrm{AI}$ as a contributor to climate change and $\mathrm{AI}$ as a contributor to fighting climate change. I have taken into account empirical findings on greenhouse gas emissions of ICT in general and AI specifically. Moreover, I have investigated proposals by AI researchers and commentators on how emissions from AI itself could be reduced and how AI could be used in mitigation and adaptation. These proposals raise ethical issues, that is, issues about what should be done: How should greenhouse gas emissions from training and use of AI be reduced? How should AI be used for mitigation? How should AI be used for adaptation? I have limited my investigation of these ethical issues to four key aspects: usefulness, freedom, justice and responsibility. I conclude that given the potential impact of AI on society, it is vital that AI companies and governments take these ethical issues seriously.

\section{References}

Andrae, A.S.G. and Edler, T. (2015), "On global electricity usage of communication technology: trends to 2030", Challenges, Vol. 6 No. 1, pp. 117-157.

Anthony, L.F.W., Kanding, B. and Selvan, R. (2020), "Carbon tracker: tracking and predicting the carbon footprint of training deep learning models", ICML Workshop on "Challenges in Deploying and Monitoring Machine Learning Systems", available at: https://arxiv.org/pdf/ 2007.03051.pdf (accessed 27 October 2021).

Belkhir, L. and Elmeligi, A. (2018), "Assessing ICT global emissions footprint: trends to 2040 and recommendations", Journal of Cleaner Production, Vol. 177, pp. 448-463.

Bostrom, N. (2011), "The ethics of artificial intelligence", in Ramsey, W. and Frankish, K. (Eds), Cambridge Handbook of Artificial Intelligence, Cambridge University Press, Cambridge.

Brockway, P.E., Sorrell, S., Semienyuk, G., Heun, M.K. and Court, V. (2021), "Energy efficiency and economy-wide rebound effects: a review of the evidence and its implications", Renewable and Sustainable Energy Reviews, Vol. 141, doi: 10.1016/j.rser.2021.110781.

Brooks, T. (2021), Climate Change Ethics for an Endangered World, Routledge, New York, NY.

Bwango, A., Wright, J., Elias, C. and Burton, I. (2000), "Reconciling national and global priorities in adaptation to climate change: with an illustration from Uganda", Environmental Monitoring and Assessment, Vol. 61 No. 1, pp. 145-159.

Carroll, A.B. and Buchholtz, A.K. (2006), Business and Society: Ethics and Stakeholder Management, 6th ed., Mason, Thomson.

Cho, R. (2018), "Artificial intelligence - a game changer for climate change and the environment", Columbia Climate School, available at: https://news.climate.columbia.edu/2018/06/05/artificialintelligence-climate-environment/ (accessed 27 October 2021).

Coeckelbergh, M. (2020), AIEthics, The MIT Press, Cambridge, MA.

Coeckelbergh, M. (2021), "AI for climate: freedom, justice, and other ethical and political challenges", AI and Ethics, Vol. 1 No. 1, pp. 67-72.

Crawford, K. (2021), Atlas of AI: Power, Politics, and the Planetary Costs of Artificial Intelligence, Yale University Press, New Haven and London.

Dhar, P. (2020), "The carbon impact of artificial intelligence", Nature Machine Intelligence, Vol. 2 No. 8, pp. 423-425, doi: 10.1038/s42256-020-0219-9.

Dignum, V. (2019), Responsible Artificial Intelligence: how to Develop and Use ai in a Responsible Way, Springer, Cham. 
Dobbe, R. and Whittaker, M. (2019), "AI and climate change: how they're connected, and what we can do about it”, AI Now Institute, available at: https:/medium.com/@AINowInstitute/ai-andclimate-change-how-theyre-connected-and-what-we-can-do-about-it-6aa8d0f5b32c (accessed 27 October 2021).

Floridi, L., Cowls, J., Beltrametti, M., Chatila, R., Chazerand, P., Dignum, V., Luetge, C., Madelin, R., Pagallo, U., Rossi, F., Schafer, B., Valcke, P. and Vayena, E. (2018), "AI4People - an ethical framework for a good ai society: opportunities, risks, principles, and recommendations", Minds and Machines, Vol. 28 No. 4, pp. 689-707, doi: 10.1007/s11023-018-9482-5.

Friedman, M. (1970), "A friedman doctrine: the social responsibility of business is to increase its profits", The Times, 13 September, section SM, p. 17, available at: https://static1.squarespace. com/static/56b7a300356fb06478dcea5a/t/5fb99036957a3511df281e4a/1605996599044/A+Fried man+doctrine $\% \mathrm{E} 2 \% 80 \% 90-+$ The + Social + Responsibility+Of+Business + Is + to+Increase + Its + Profits +-+ The + New + York+Times.pdf (accessed 27 October 2021).

Gailhofer, P., Herold, A., Schemmel, J.P., Scherf, C.-S., Urrutia, C., Köhler, A.R. and Braungardt, S. (2021), "The role of artificial intelligence in the european green deal", Policy Department for Economic, Scientific and Quality of Life Policies, European Parliament, EU, available at: www.europarl. europa.eu/RegData/etudes/STUD/2021/662906/IPOL_STU(2021)662906_EN.pdf (accessed 27 October 2021).

Gardiner, S.M. (2011), A Perfect Moral Storm: The Ethical Tragedy of Climate Change, Oxford, Oxford University Press.

Gardiner, S.M., Caney, S., Jamieson, D. and Shue, H. (Eds) (2010), Climate Ethics: Essential Readings, Oxford, Oxford University Press.

Hausfather, Z. and Peters, G.P., (2020), "Emissions - the 'business as usual' story is misleading", Nature, Vol. 577 No. 7792, Vol. 5. pp. 618-620, doi: 10.1038/d41586-020-00177-3.

Hazas, M., Morley, J., Bates, O. and Friday, (2016), "Are there limits to growth in data traffic? On time use, data generation and speed", Proceedings of the Second Workshop on Computing within Limits, available at: https://computingwithinlimits.org/2016/papers/a14-hazas.pdf (accessed 27 October 2021).

Heatley, B. (2017), "Paris: optimism, pessimism and realism”, Global Discourse, Vol. 7 No. 1, pp. 10-22.

Henderson, P., Hu, J., Romoff, J., Brunskill, E., Jurafsky, D. and Pineau, J. (2020), "Towards the systematic reporting of the energy and carbon footprints of machine learning", Journal of Machine Learning Research, Vol. 21, pp. 1-43.

Intergovernmental Panel on Climate Change (IPCC) (2021), "Summary for policy makers", in Masson-Delmotte, V., Zhai, P., Pirani, A., Connors, S.L., Péan, C., Berger, S., Caud, N., Chen, Y., Goldfarb, L., Gomis, M.I., Huang, M., Leitzell, K., Lonnoy, E., Matthews, J.B.R., Maycock, T.K., Waterfield, T., Yelekçi, O., Yu, R. and Zhou, B. (Eds), Climate Change 2021: The Physical Science Basis. Contribution of Working Group I to the Sixth Assessment Report of the Intergovernmental Panel on Climate Change, Cambridge University Press, Cambridge, pp. 1-41, available at: www.ipcc.ch/report/ sr15/summary-for-policymakers/ (accessed 27 October 2021).

International Energy Agency (IEA) (2017), "Digitalization and energy", available at: https://iea.blob. core.windows.net/assets/b1e6600c-4e40-4d9c-809d-1d1724c763d5/DigitalizationandEnergy3.pdf (accessed 27 October 2021).

Jones, N. (2018), "How to stop data centres from gobbling up the world's electricity: the energyefficiency drive at the information factories that serve us facebook, google and bitcoin”, Nature, Vol. 561 No. 7722, pp. 163-166, doi: 10.1038/d41586-018-06610-y.

Lacoste, A., Luccioni, A., Schmidt, V. and Dandres, T. (2019), "Quantifying the carbon emissions of machine learning", available at: https://arxiv.org/pdf/1910.09700.pdf (accessed 27 October 2021).

Malliaraki, E. (2020), "AI and climate change: the promise, the perils and pillars for action”, EIT Climate-KIC, available at: www.climate-kic.org/opinion/ai-and-climate-change-the-promise-theperils-and-pillars-for-action/ (accessed 27 October 2021). 
JICES

21,1

Michaels, R.J. (2012), "Energy efficiency and climate policy: the rebound dilemma", Institute for Energy Research, available at: www.instituteforenergyresearch.org/wp-content/uploads/2012/ 07/NJI_IER_MichaelsStudy_WEB_20120706_v5.pdf (accessed 27 October 2021).

Millward-Hopkins, J., Steinberger, J.K., Rao, N.B. and Oswald, Y. (2020), "Providing decent living with minimum energy: a global scenario", Global Environmental Change, Vol. 65, doi: 10.1016/j. gloenvcha.2020.102168.

Posner, E.A. and Weisbach, D. (2010), Climate Change Justice, Princeton University Press, Princeton.

Prahl, A. and Hofmann, E. (2016a), "Non-market-based climate policy instruments applied in the EU", Climate Policy Info Hub available at: http://climatepolicyinfohub.eu/non-market-based-climatepolicy-instruments (accessed 27 October 2021).

Prahl, A. and Hofmann, E. (2016b), "Market-based climate policy instruments", Climate Policy Info Hub, available at: http://climatepolicyinfohub.eu/market-based-climate-policy-instruments (accessed 27 October 2021).

Ripple, W.J., Wolf, C., Newsome, T.M., Barnard, P. and Moomaw, W.R. (2020), "World scientists' warning of a climate emergency", BioScience, Vol. 70 No. 1, pp. 8-12.

Rolnick, D., Donti, P.L., Kaack, L.H., Kochanski, K., Lacoste, A., Sankaran, K., Ross, A.S., Milojevic-Dupont, N., Jaques, N., Waldman-Brown, A., Luccioni, A., Maharaj, T., Sherwin, E.D., Mukkavilli, S.K., Körding, K.P., Gomes, C., Ng, A.Y., Hassabis, D., Platt, J.C., Creutzig, F., Chayes, J. and Bengio, Y. (2019), "Tackling climate change with machine learning", available at: https://arxiv.org/pdf/ 1906.05433.pdf (accessed 27 October 2021).

Schwalm, C.R., Glendon, S. and Duffy, P.D. (2020), "RCP8.5 tracks cumulative CO2 emissions", Proceedings of the National Academy of Sciences, Vol. 117 No. 33, pp. 19656-19657.

Singer, P. (2010), "One atmosphere”, in Gardiner, S.M., Caney, S., Jamieson, D. and Shue, H. (Eds), Climate Ethics: Essential Readings, Oxford University Press, Oxford, pp. 181-199.

Strubell, E., Ganesh, A. and Callum, A.M. (2019), "Energy and policy considerations for deep learning in NLP”, available at: https://arxiv.org/pdf/1906.02243.pdf (accessed 27 October 2021).

Tech Workers Coalition (2019), "Tech climate strike", available at: https://techworkerscoalition.org/ climate-strike/ (accessed 27 October 2021).

Thaler, R. and Sunstein, C. (2009), "Nudge: Improving decisions about health, wealth, and happiness", Revised and Expanded Edition, Penguin Books, New York, NY.

Toews, R. (2020), “Deep learning's carbon emissions problem”, Forbes, 17 June, available at: www. forbes.com/sites/robtoews/2020/06/17/deep-learnings-climate-change-problem/?sh=450c5dc66b43 (accessed 27 October 2021).

Uddin, M. (2020), “Artificial intelligence to combat climate change: a legal-ethical perspective”, Dhaka Tribune, 21 May, available at: www.dhakatribune.com/climate-change/2020/05/21/artificialintelligence-to-combat-climate-change-a-legal-ethical-perspective (accessed 27 October 2021).

United Nations Framework Convention on Climate Change (UNFCCC) (1992), "The convention”, available at: https://unfccc.int/resource/docs/convkp/conveng.pdf (accessed 27 October 2021).

United Nations Framework Convention on Climate Change (UNFCCC) (2015), "Paris agreement", available at: https://unfccc.int/sites/default/files/english_paris_agreement.pdf (accessed 27 October 2021).

United Nations General Assembly (UNGA) (2015), "Transforming our world: the 2030 agenda for sustainable development”, A/RES/70/1, available at: https://sdgs.un.org/2030agenda (accessed 27 October 2021).

Unwin, T. (2020), "Digital technologies are part of the climate change problem”, ICTWorks, available at: www.ictworks.org/digital-technologies-climate-change-problem/\#.YXld2y-16gQ (accessed 27 October 2021). 
Victor, D.G. (2019), "How artificial intelligence will affect the future of energy and climate", The Brookings Institution, available at: www.brookings.edu/research/how-artificial-intelligence-willaffect-the-future-of-energy-and-climate/ (accessed 27 October 2021).

Vinuesa, R., Azizpour, H., Leite, I., Balaam, M., Dignum, V., Domisch, S., Felländer, A., Langhans, S.D., Tegmark, M. and Nerini, F.F. (2020), "The role of artificial intelligence in achieving the sustainability development goals", Nature Communications, Vol. 11 No. 1, doi: 10.1038/s41467019-14108-y.

Walleser, E. (2021), "Artificial intelligence has an enormous carbon footprint”, Towards Data Science,

Artificial intelligence and climate change available at: https://towardsdatascience.com/artificial-intelligence-has-an-enormous-carbonfootprint-239290ebffe (accessed 27 October 2021).

Walls, J. (2021), "Freedom and climate change: acting now to retain future options", St. Gallen Symposium, Switzerland, available at: www.symposium.org/articles/freedom-and-climatechange-acting-now-retain-future-options (accessed 27 October 2021).

\section{Corresponding author}

Anders Nordgren can be contacted at: anders.nordgren@liu.se

For instructions on how to order reprints of this article, please visit our website: www.emeraldgrouppublishing.com/licensing/reprints.htm Or contact us for further details: permissions@emeraldinsight.com 